\title{
Identification of key pathways and genes in lung carcinogenesis
}

\author{
XIANG JIN ${ }^{1}$, XINGANG LIU $^{2}$, ZHEN ZHANG $^{3}$, YINGHUI GUAN ${ }^{1}, \mathrm{REN} \mathrm{XV}^{1}$ and $\mathrm{JUN} \mathrm{LI}^{4}$ \\ Departments of ${ }^{1}$ Respiration, ${ }^{2}$ ICU and ${ }^{3}$ PICU, The First Hospital of Jilin University, Changchun, Jilin 130021; \\ ${ }^{4}$ Department of Pneumology, Jinan Central Hospital, Jinan, Shandong 250013, P.R. China
}

Received April 25, 2016; Accepted March 14, 2018

DOI: $10.3892 / \mathrm{ol} .2018 .9203$

\begin{abstract}
The present study aimed to identify key pathways and genes in the pathogenesis of lung cancer. The GSE10072 dataset was downloaded from the Gene Expression Omnibus database. Protein-protein interaction data were collected from Human Protein Reference Database, and 201 pathways were downloaded from the Kyoto Encyclopedia of Genes and Genomes database. Signaling network impact analysis was performed to identify enriched pathways, followed by the construction of a pathway-pathway crosstalk network. Benzopyrene was used to treat normal human lung cells at concentrations of $0.01,0.1,1$ and $10 \mu \mathrm{M}$, and cell viability was measured. Furthermore, growth arrest and DNA damage inducible $\beta$ (GADD45B), p53, cyclin $\mathrm{B}$, Akt and nuclear factor $(N F)-\kappa B$ protein levels were also measured via western blotting. Impact analysis identified 11 enriched lung cancer-associated KEGG pathways, including 'complement and coagulation cascades', 'ECM-receptor interaction', 'P53 signaling pathway', 'cell adhesion molecules' and 'focal adhesion'. In addition, cell cycle, 'drug metabolism-cytochrome P450', 'metabolic pathways', 'pathways in cancer', 'focal adhesion' and 'antigen processing and presentation' were central in the pathway-pathway cross-talk network. Furthermore, the upregulated gene GADD45B was associated with three of the pathways, including an activated pathway ('MAPK signaling pathway') and two repressed pathways ('cell cycle' and 'P53 pathway'). Western blotting demonstrated that the expression of NF- $\kappa B$, Akt and GADD45B increased over time in lung cells treated with benzopyrene, whereas the expression levels of cyclin B and P53 decreased. In conclusion, GADD45B may contribute to lung carcinogenesis via affecting the MAPK, P53 signaling and cell cycle pathways.
\end{abstract}

Correspondence to: Dr Xingang Liu, Department of ICU, The First Hospital of Jilin University, 71 Xinmin Avenue, Changchun, Jilin 130021, P.R. China

E-mail: liuxgang4@sina.com

Dr Jun Li, Department of Pneumology, Jinan Central Hospital, 105 Jiefang Road, Jinan, Shandong 250013, P.R. China

E-mail: 1ijun3706@163.com

Key words: lung cancer, signaling pathway, pathway-pathway crosstalk, cell viability, protein expression

\section{Introduction}

Lung cancer is one of the most common types of cancer (1). Lung cancer has two main histological types: Non-small cell lung cancer (NSCLC; 80.4\%) and SCLC (16.8\%) (2); however, the underlying mechanisms for the development of lung cancer are not yet completely characterized.

Accumulated genetic abnormalities are associated with cancer. Somatic mutations in a number of genes, including epidermal growth factor receptor $(E G F R), P 53, K R A S$, $B R A F$, Erb-B2 receptor tyrosine kinase 2 (ERBB2), MET, serine/threonine kinase 11, PIK3CA and Parkin RBR E3 ubiquitin protein ligase, have been identified in patients with lung cancer $(3,4)$. Gene amplifications, including of $E G F R$, ERBB2, MET, PIK3CA and NK2 homeobox 1, have also been detected in lung cancer (5). A number of single nucleotide polymorphisms (SNPs) are associated with lung cancer susceptibility, including in interleukin-1, cytochrome P450, a 5'SNP in the ERCC excision repair 6, chromatin remodeling factor gene and SNPs in the nicotinic acetylcholine receptor gene cluster on chromosome 15q25.1 (6-9). Genetic abnormalities have been identified in numerous pathways, including the Notch (10), EGFR (11), PI3K (12), phosphatase and tensin homolog/phospho-Akt/P53 (13), mitogen-activated protein kinase (MAPK) (14) and cell cycle pathways.

In the past decade, there has been a pervasive application of high-throughput molecular technologies, including microarrays, in lung cancer research (15-17), which has greatly enriched the knowledge of the pathogenesis of the disease, and may potentially provide markers for the prognosis and targeted therapy of lung cancer. By enrolling 105 subjects in an Environment And Genetics in Lung cancer Etiology study (http://dceg.cancer.gov/eagle), Landi et al (18) produced a microarray dataset that included 107 expression values from tumor $(\mathrm{n}=58)$ and non-tumor tissues $(\mathrm{n}=49)$ from 74 subjects (non-smokers, $n=20$; former smokers, $n=26$; current smokers, $\mathrm{n}=28$ ). Using this microarray analysis, 122 genes were identified that were differentially expressed between the tumor and non-tumor samples. In addition, several crucial smoking-associated genes and pathways were identified in the study, and a number of these, including Nima related kinase 2 and TTK protein kinase, were experimentally validated; however, the relationship between these genes and pathways were not considered in the original study.

In the present study, based on the microarray dataset produced by Landi et al (18), GSE10072, a novel pathway-pathway 
crosstalk approach was employed to identify pathways and genes that may have critical roles in the pathogenesis of lung cancer, and a number of the identified genes were experimentally validated.

\section{Materials and methods}

Source of pathway and microarray data. Protein-protein interaction data were downloaded from the Human Protein Reference Database (http://www.hprd.org/), and 201 lung cancer pathways were downloaded from the Kyoto Encyclopedia of Genes and Genomes (KEGG, http://www.kegg.jp/) database $(19,20)$ using 'lung cancer' as the search term.

The raw data of the gene expression profile dataset GSE10072 in the '.CEL' format were downloaded from the Gene Expression Omnibus database (http://www.ncbi.nlm.nih.gov/geo/).

Identification of differentially expressed genes (DEGs). The raw downloaded data were preprocessed and normalized using the R/Bioconductor package Affy with the Robust Multichip Average method for single-channel Affymetrix chips (21). A one-way analysis of variance was applied to each probe set to identify those that significantly changed expression level over time, as previously described (22). $\mathrm{P}<0.05$ was considered to indicate a statistically significant result; the raw P-value was adjusted with the Bonferroni method (23).

Impact analysis. The pathway impact analysis as described by Draghici et al (24) was adopted, which considers the statistical significance of the enrichment of KEGG pathways, while also considering other crucial factors, including the magnitude of expression change for each gene, the topology of the signaling pathway, and the interactions between signaling pathways.

Construction of pathway-pathway crosstalk network. A hyper geometric distribution framework was applied to evaluate the significance of all non-empty intersections between two pathways, as previously described (25): Fisher's exact test computed the probability, $p^{*}$ using hyper geometric distribution with the parameters $\left(S, N_{G}, N\right)$.

$$
p^{*}=p\left(X=\alpha \mid S, N_{G}, N\right)=\frac{\left(\begin{array}{l}
S \\
\alpha
\end{array}\right)\left(\begin{array}{l}
N-S \\
N_{G}-\alpha
\end{array}\right)}{\left(\begin{array}{l}
N \\
N_{G}
\end{array}\right)}
$$

Where $\alpha$ was the number of DEGs in the pathway intersection; $S$, the number of DEGs in the pathway union; $N_{G}$, the number of genes in the pathway intersection; and $N$, the number of genes in the pathway union.

The P-value to reject the null hypothesis with a probability of $\left\langle p^{*}\right.$ was calculated using the sum of the probabilities with the same marginal totals, i.e.:

$$
p=\sum \frac{\left(\begin{array}{l}
S \\
i
\end{array}\right)\left(\begin{array}{l}
N-S \\
N_{G}-i
\end{array}\right)}{\left(\begin{array}{l}
N \\
N_{G}
\end{array}\right)}
$$

Table I. Significantly enriched Kyoto Encyclopedia of Genes and Genomes pathways in GSE10072.

\begin{tabular}{lrc}
\hline Pathway & Impact factor & P-value \\
\hline $\begin{array}{l}\text { Complement and coagulation } \\
\text { cascades }\end{array}$ & 17.258 & $2.08 \times 10^{-7}$ \\
ECM-receptor interaction & 14.266 & $3.90 \times 10^{-6}$ \\
P53 signaling pathway & 9.017 & $3.41 \times 10^{-4}$ \\
Cell adhesion molecules & 70.734 & $4.42 \times 10^{-4}$ \\
Focal adhesion & 9.283 & $1.17 \times 10^{-3}$ \\
Cell cycle & 6.673 & $3.36 \times 10^{-3}$ \\
Renin-angiotensin system & 5.778 & $8.30 \times 10^{-3}$ \\
PPAR signaling pathway & 5.733 & $1.54 \times 10^{-2}$ \\
TGF-beta signaling pathway & 6.352 & $2.24 \times 10^{-2}$ \\
Leukocyte transendothelial & 114.039 & $2.34 \times 10^{-2}$ \\
migration & & \\
migration Tight junction & 6.133 & $4.85 \times 10^{-2}$ \\
\hline
\end{tabular}

This procedure gave a two-tailed probability for a Fisher's exact test. $\mathrm{P}<0.05$ was considered to indicate a statistically significant result, indicative of the association of two pathways.

Analysis of cross-talk between pathways. The state of a pathway was initially determined. A pathway was considered to be activated when it met the following criteria: i) Number of DEGs in the pathway >10; ii) Q-value [(number of upregulated DEGs in the pathway-number of downregulated DEGs in the pathway)/total number of genes in the pathway] $>0.5$. A repressed pathway met the two criteria: i) Number of DEGs in this pathway $>10$; ii) Q-value $<-0.5$. Next, pairs of pathways sharing common DEGs were identified, and these DEGs were listed.

Cell culture and treatment. Normal lung K562 cells were purchased from the American Type Culture Collection (Manassas, VA, USA). The cells were grown in RPMI-1640 (Gibco; Thermo Fisher Scientific, Inc., Waltham, MA, USA) supplemented with $10 \%$ heat-inactivated fetal bovine serum (Gibco; Thermo Fisher Scientific, Inc.) and $100 \mathrm{U} / \mathrm{ml}$ penicillin and streptomycin, in a humidified atmosphere with 5\% $\mathrm{CO}_{2}$ at $37^{\circ} \mathrm{C}$. To maintain drug resistance, adriamycin was supplemented at regular intervals for 2 weeks prior to any experiment. Benzopyrene was used to treat the cells at concentrations of $0.01,0.1,1$ and $10 \mu \mathrm{M}$ in the subsequent assays.

Measurement of cell viability. Cell proliferation was measured using an MTT assay. Cells $\left(2 \times 10^{5}\right.$ cells $\left./ \mathrm{ml}\right)$ were seeded in 96-well plates with increasing concentrations of adriamycin, SNX-2112 and 17-AAG. After incubation at $37^{\circ} \mathrm{C}$ for 24,48 and $72 \mathrm{~h}, 5 \mathrm{mg} / \mathrm{ml}$ MTT solution was added for incubation for $4 \mathrm{~h}$. Then, $100 \mu \mathrm{l} / \mathrm{well}$ DMSO was added to solubilize the formazan crystals. Cell viability was assessed by measuring absorbance at $570 \mathrm{~nm}$ using a microplate reader (Bio-Rad Laboratories, Inc., Hercules, CA, USA).

Western blot analysis. Cells were first lysed in lysis buffer (Sangon Biotech Co., Ltd., Shanghai, China) and then total 

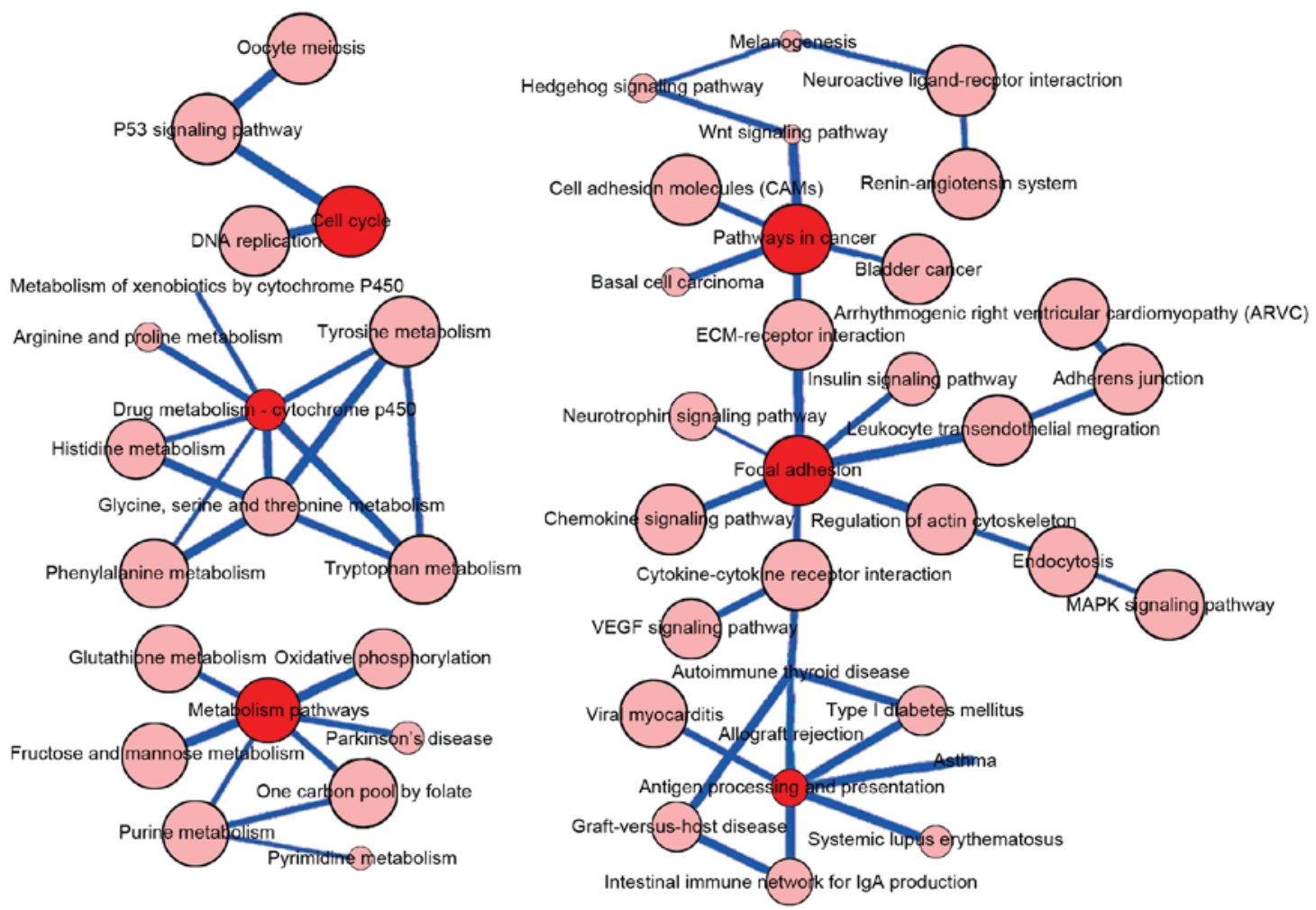

Figure 1. Network of pathway-pathway crosstalk for the GSE10072 dataset. The nodes represent each pathway, with the edges representing the crosstalk between the pathways. The thickness of the edges represents the strength of the pathway interactions. Red and pink represent primary and secondary nodes respectively.

protein was extracted. Followed by protein concentration was measured by the bicinchoninic acid method. Equal aliquots (20 $\mu \mathrm{g}$ protein per lane) of protein lysate were separated by 8-12\% SDS-PAGE and transferred to a polyvinylidene difluoride membrane. Subsequent to blocking with $5 \%$ skimmed milk at $37^{\circ} \mathrm{C}$ for $1 \mathrm{~h}$, Western blots were probed with primary antibodies against nuclear factor $(\mathrm{NF})-\kappa \mathrm{B}(1: 1,000$; cat no. ab32360; Abcam, Cambridge, MA, USA), Akt (1:1,000; cat no. ab126811; Abcam), cyclin B (1:1,000; cat no. ab18221; Abcam), P53 (1:1,000; cat no. ab21985; Abcam), growth arrest and DNA damage inducible $\beta$ (GADD45B) $(1: 1,000$; cat no. ab128920; Abcam) and $\beta$-actin (1:1,000; cat no. ab6276; Abcam) overnight at $4^{\circ} \mathrm{C}$. Three consecutive washes were performed for $10 \mathrm{~min}$ in $\mathrm{PBS}$-Tween, followed by incubation with the alkaline phosphatase-conjugated goat anti-rabbit IgG secondary antibody (1:5,000; cat no. ab6722; Abcam) diluted in $5 \%$ skimmed milk at room temperature for $1 \mathrm{~h}$. The immunoblots were visualized with enhanced chemiluminescence (GE Healthcare, Chicago, IL, USA) and autoradiography. The experiments were repeated three times, and the results were detected using the Image Lab software (version 4.1; Bio-Rad Laboratories, Inc.) on ChemiDoc MP imaging system (Bio-Rad Laboratories, Inc.).

Statistical analysis. All data were presented as the mean \pm standard deviation. Statistical analysis was performed by one-way analysis of variance with a Bonferroni post hoc test in SPSS software (version 13.0; SPSS, Inc., Chicago, IL, USA). $\mathrm{P}<0.05$ was considered to indicate a statistically significant difference.

\section{Results}

Identification of DEGs. Using a threshold of $\mathrm{P}<0.05$, the genes with significantly differential expression were analyzed. A total of 1,763 DEGs were identified, of which 662 were associated with KEGG pathways.

Result of impact analysis. A total of 11 pathways were identified in the pathway impact analysis. Of these, 'complement and coagulation cascades', 'ECM-receptor interaction', 'P53 signaling pathway', 'cell adhesion molecules (CAMs)', 'focal adhesion' and 'cell cycle' were the top five pathways by impact factor value (Table I).

Analysis of cross-talk between pathways. It was determined that the 'cell cycle', 'drug metabolism-cytochrome P450', 'metabolic pathways', 'pathways in cancer', 'focal adhesion' and 'antigen processing and presentation' KEGG pathways were central in the pathway-pathway crosstalk network (Fig. 1).

Using the criteria defined for activated and repressed pathways, 2 pathways ('cell cycle' and 'P53 signaling pathway') were repressed, and 10 pathways were activated (Table II). The common DEGs between the pathways are listed in Table III. GADD $45 B$ was associated with three enriched pathways, including the activated 'MAPK signaling pathway' and the repressed 'cell cycle' and 'P53 signaling pathway' terms (Fig. 2).

Measurement of cell viability and western blot analysis. Benzopyrene treatment reduced the viability of lung cells at 
Table II. Status of the Kyoto Encyclopedia of Genes and Genomes pathways associated with the differentially expressed genes in lung cancer.

\begin{tabular}{lcccr}
\hline & \multicolumn{2}{c}{ DEGs } & \\
\cline { 2 - 3 } Pathway & Upregulated & Downregulated & Both & Q-value \\
\hline Cell cycle & 2 & 11 & 13 & -0.6923 \\
P53 signaling pathway & 2 & 8 & 10 & -0.6000 \\
Cytokine-cytokine receptor interaction & 13 & 3 & 16 & 0.6250 \\
Tight junction & 9 & 2 & 11 & 0.6364 \\
Neuroactive ligand-receptor interaction & 15 & 3 & 18 & 0.6667 \\
Chemokine signaling pathway & 11 & 2 & 13 & 0.6923 \\
Complement and coagulation cascades & 14 & 1 & 16 & 0.7500 \\
Axon guidance & 9 & 1 & 10 & 0.8000 \\
Vascular smooth muscle contraction & 12 & 1 & 13 & 0.8462 \\
MAPK signaling pathway & 13 & 0 & 11 & 0.8571 \\
Regulation of actin cytoskeleton & 11 & 0 & 10 & 1.0000 \\
Endocytosis & 10 & 1.0000 \\
\hline
\end{tabular}

Table III. Differentially expressed genes associated with multiple enriched Kyoto Encyclopedia of Genes and Genomes pathways.

\begin{tabular}{lll}
\hline Pathway 1 & \multicolumn{1}{c}{ Pathway 2 } & \multicolumn{1}{c}{ Gene IDs } \\
\hline Cytokine-cytokine receptor interaction & Chemokine signaling pathway & $6359,1524,2921,2920,6387$ \\
Neuroactive ligand-receptor interaction & Vascular smooth muscle contraction & $1906,10203,1909,185$ \\
MAPK signaling pathway & Regulation of actin cytoskeleton & $2264,6237,2263$ \\
MAPK signaling pathway & Endocytosis & $2264,7048,2263$ \\
Regulation of actin cytoskeleton & Endocytosis & $2264,2263,8395$ \\
Tight junction & Regulation of actin cytoskeleton & $10398,6237,4628$ \\
Cytokine-cytokine receptor interaction & Neuroactive ligand-receptor interaction & 3953,2690 \\
Cytokine-cytokine receptor interaction & Chemokine signaling pathway & 10563,9547 \\
Tight junction & Vascular smooth muscle contraction & 10398,4629 \\
Tight junction & MAPK signaling pathway & 6237,10000 \\
Vascular smooth muscle contraction & Regulation of actin cytoskeleton & 10398,4638 \\
Cell cycle & P53 signaling pathway & 4616 \\
Cell cycle & MAPK signaling pathway & 4616 \\
Chemokine signaling pathway & Axon guidance & 6387 \\
Chemokine signaling pathway & Vascular smooth muscle contraction & 115 \\
Chemokine signaling pathway & MAPK signaling pathway & 10000 \\
Chemokine signaling pathway & Regulation of actin cytoskeleton & 5295 \\
Chemokine signaling pathway & Endocytosis & 2869 \\
Cytokine-cytokine receptor interaction & Axon guidance & 6387 \\
Cytokine-cytokine receptor interaction & MAPK signaling pathway & 7048 \\
Cytokine-cytokine receptor interaction & Endocytosis & 7048 \\
Neuroactive ligand-receptor interaction & Complement and coagulation cascades & 728 \\
Neuroactive ligand-receptor interaction & Endocytosis & 154 \\
P53 signaling pathway & MAPK signaling pathway & 4616 \\
Tight junction & Chemokine signaling pathway & 10000 \\
Vascular smooth muscle contraction & MAPK signaling pathway & 5319 \\
Vascular smooth muscle contraction & MAPK signaling pathway & 5321 \\
& &
\end{tabular}

all concentrations from $72 \mathrm{~h}$ (Fig. 3). GADD45B, P53, cyclin , Akt and NF- $\mathrm{KB}$ protein levels were detected by Western blotting (Fig. 4). Western blotting demonstrated that the expression of NF-kB, Akt and GADD45B increased over time 


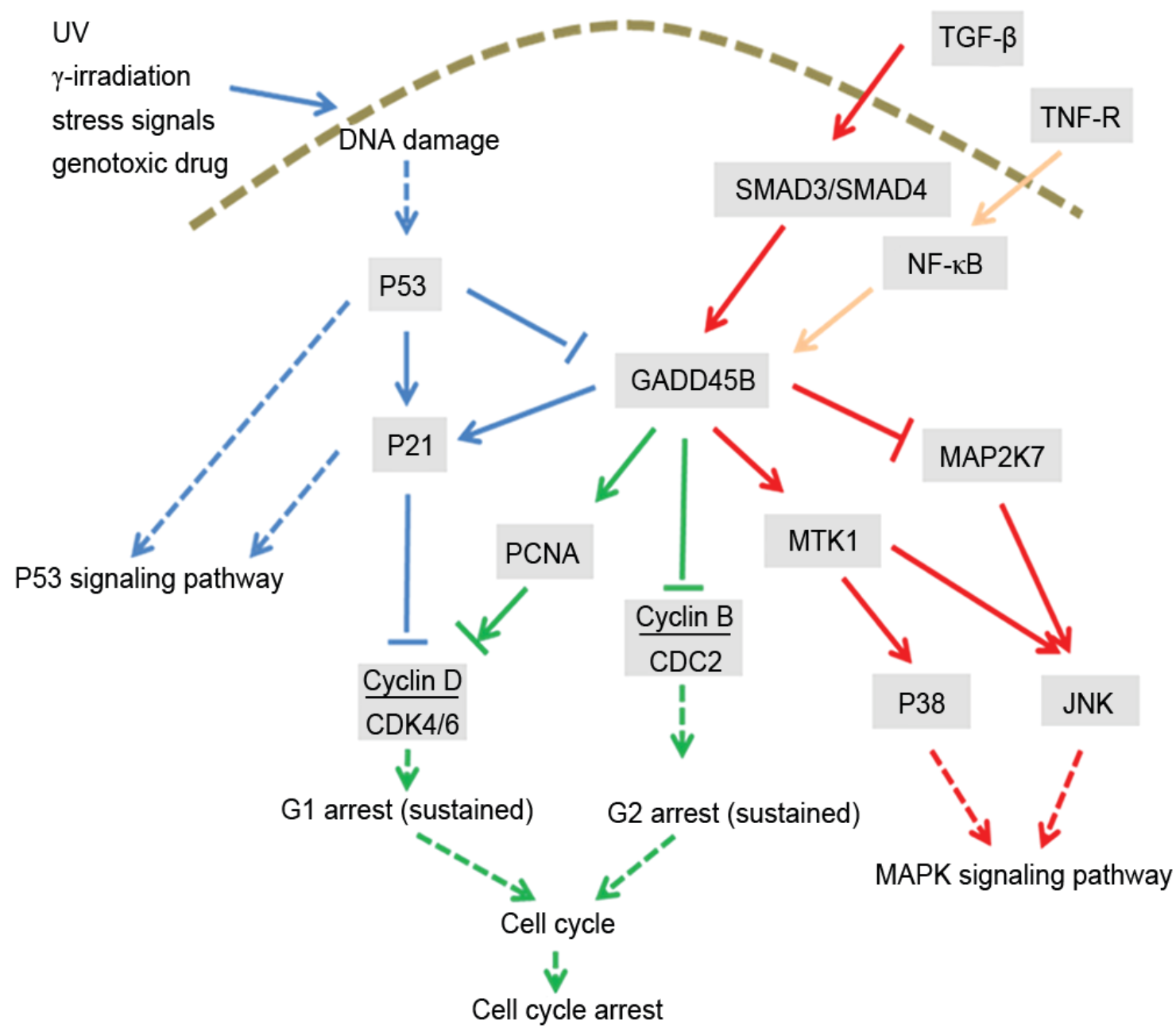

Figure 2. Schematic diagram of the pathway-pathway crosstalk via GADD45B. In this figure, the blue arrows represent the interaction with the P53 signaling pathway, the green arrows represent the interaction with the cell cycle pathway and the red arrows represent the interaction with the MAPK signaling pathway. Yellow arrows represent the interactions between GADD45B and genes that are not associated with 'P53 signaling pathway', 'MAPK signaling pathway' or 'cell cycle'. Solid lines represent direct interactions; dashed lines represent indirect effects. GADD45B, growth arrest and DNA damage inducible $\beta$; UV, ultraviolet radiation; TGF- $\beta$, transforming growth factor- $\beta$; TNF-R, tumor necrosis factor receptor; NF- $\mathrm{K}$, nuclear factor- $\mathrm{kB}$; CDK, cyclin-dependent kinase; CDC2, cyclin-dependent kinase 1; PCNA, proliferating cell nuclear antigen; MAPK, mitogen-activated protein kinase; MTK1, MAPK kinase kinase 4; MAP2K7, MAPK kinase 7; JNK, c-Jun N-terminal kinase.

in lung cells treated with benzopyrene, whereas the expression of cyclin B and P53 was decreased (Fig. 5).

\section{Discussion}

In the present study, significantly enriched pathways were identified with impact analysis, and a pathway-pathway crosstalk network was constructed. GADD45B was identified as a connection between a number of the enriched pathways, and experimental validation of the expression of this gene and associated pathways was performed.

In comparison to classical pathway analysis, impact analysis also considers the over-representation of DEGs in a given pathway and the abnormal perturbation of that pathway, as measured by the expression changes across the pathway topology (26). Previously, the roles of the P53 signaling pathway, cell adhesion, focal adhesion and the cell cycle in the pathogenesis of lung cancer have been confirmed and studied extensively $(27,28)$. In contrast, the complement and coagulation cascades in this disease have been less reported.
Corrales et al (29), reported the activation of the complement system by detecting the anaphylatoxin $\mathrm{C} 5 \mathrm{a}$, a potent immune mediator generated subsequent to complement activation in lung cancer cell lines. Plasminogen activator inhibitor (PAI) variants PAI-1 A15T and PAI-2 S413C influence the prognosis of patients with lung cancer (30), and PAI-I has been demonstrated to inhibit the activation of the coagulation system (31). Levels of the erythrocyte complement receptor 1 were significantly lower in patients with small cell lung cancer (32). A previous study revealed that activated coagulation factor $\mathrm{X}$ inhibited the migration of lung cancer cells and may serve a key role in cell migration (33). Thus, it was indicated that the complement and coagulation cascades may also serve an important role in the pathogenesis of lung cancer.

The pathway-pathway cross-talk network indicated the central roles of 'cell cycle', 'drug metabolism-cytochrome P450', 'metabolic pathways', 'pathways in cancer', 'focal adhesion' and 'antigen processing and presentation'; metabolism-associated pathways may therefore be particularly important in the pathogenesis of lung cancer. Tumor cells sustain high 


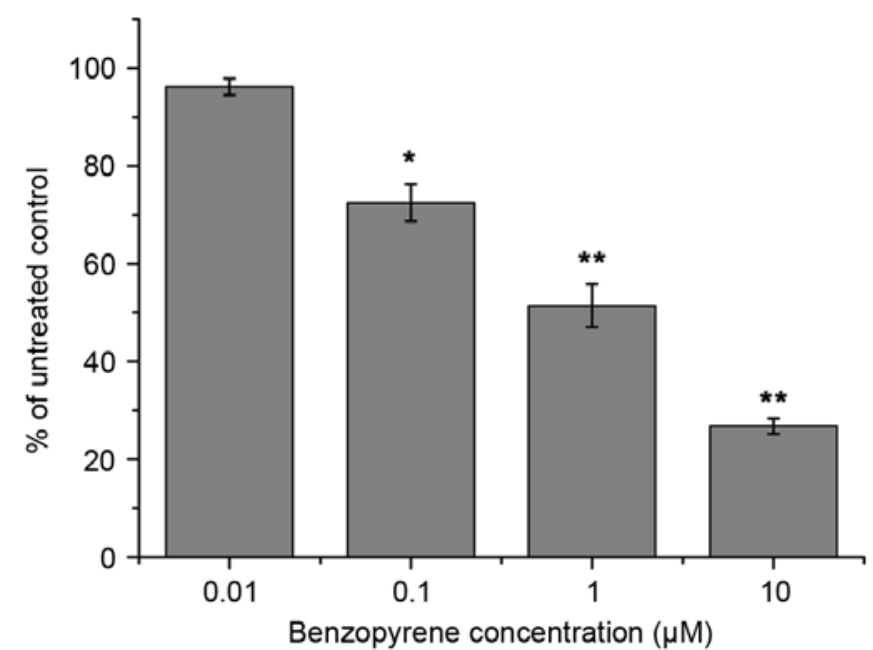

Figure 3. MTT assay of human bronchial epithelial cells cultured for $72 \mathrm{~h}$ with $0.01,0.1,1$ or $10 \mu \mathrm{M}$ benzopyrene. The data are presented as means \pm standard deviation. ${ }^{*} \mathrm{P}<0.05$ and ${ }^{* *} \mathrm{P}<0.01$ relative to the untreated control.

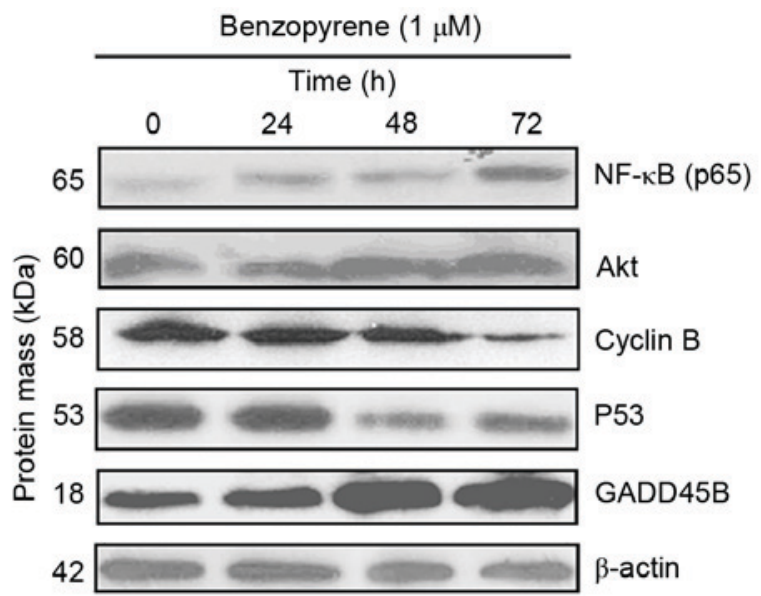

Figure 4. Identification of the GADD45B, P53, cyclin B, Akt and NF-kB protein expression levels using western blot analysis. GADD45B, growth arrest and DNA damage inducible $\beta ; \mathrm{NF}-\kappa \mathrm{B}$, nuclear factor- $\kappa \mathrm{B}$.

rates of glycolysis even in aerobic conditions to maintain their rapid growth; alterations in in primary metabolites (34) and glycolysis-associated enzymes, including hexokinase II and glyceraldehyde-3-phosphate dehydrogenase (35,36), have been identified in lung cancer. Additionally, the alteration of metabolic pathways may affect the efficacy of anti-tumor drugs, e.g. the glutathione metabolic pathway, which is involved in the detoxification or inactivation of platinum drugs (37). The cytochromes P450 are a group of enzymes that catalyze the oxidative biotransformation of the majority of drugs and other lipophilic xenobiotics (38).

In the present study, $G A D D 45 B$, an upregulated gene, was determined to be a common link between three KEGG pathways, including the upregulated 'MAPK signaling pathway' and the repressed 'cell cycle' and 'P53 signaling pathway'. It was therefore considered to potentially have an important role in the pathogenesis of lung cancer. GADD $45 B$, encoding MyD118, is part of a highly conserved Gadd45 gene family with GADD45A, encoding GADD45, and GADD45G,

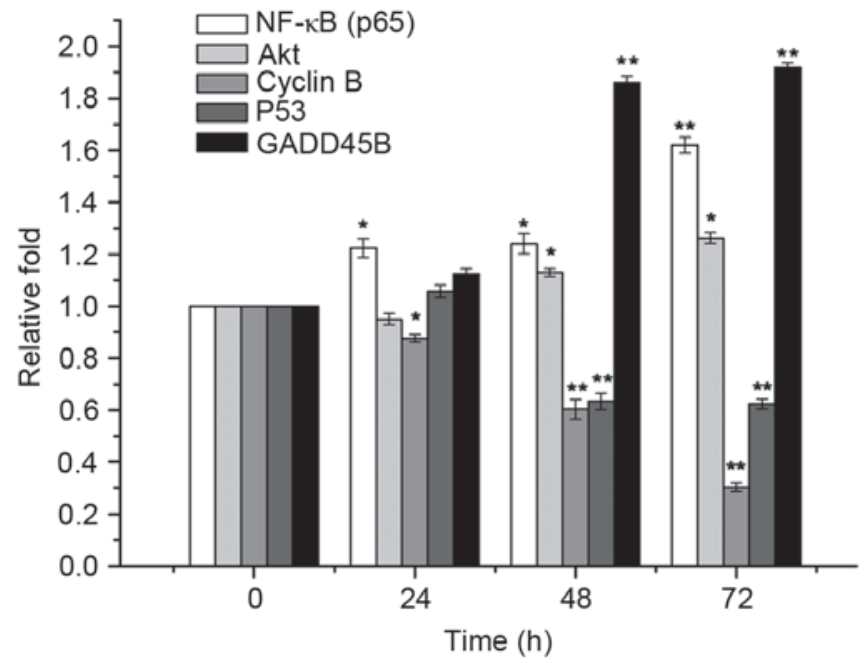

Figure 5. Quantification of the GADD45B, P53, cyclin B, Akt and NF- $\kappa$ B protein levels from the western blot analysis. ${ }^{*} \mathrm{P}<0.05$ and ${ }^{* *} \mathrm{P}<0.01$ compared with 0 h. GADD45B, growth arrest and DNA damage inducible $\beta$; NF- $\kappa B$, nuclear factor- $\mathrm{\kappa} B$.

encoding CR6. Gadd45 proteins have been implicated for their involvement in tumorigenesis (39) and age-associated pathologies (40); however, MyD118, GADD45 and CR6 are considered to have similar but not identical functions via different apoptotic and growth suppressive pathways (41). The MAPK signaling pathway has been confirmed to have an important role in the pathogenesis of lung cancer (42). In the present study, this signaling pathway was activated in patients with lung cancer. Gupta et al (43) demonstrated that GADD45B promotes cell survival via activation of the GADD45a-P38-NF- $\kappa B$ pathway and inhibition of the MAPK kinase 4-c-Jun N-terminal kinases (JNK) pathway. P38 and JNK are members of the MAPK family (44). TGF- $\beta$ can activate Smad by phosphorylation (45). One previous study demonstrates that following the induction by TGF- $\beta$, Smad transcription factors activate P38 via GADD45B (46). Another study demonstrates that SMAD3 and SMAD4 can activate GADD45B following the induction by TGF- $\beta$ (47). GADD45B and GADD45G are cyclin-dependent kinase 2/cyclin B1 kinase inhibitors, and thus function in in $\mathrm{G}_{2} / \mathrm{M}$ cell cycle arrest (48). This is in accord with the observation in the present study that the cell cycle pathway was repressed.

It was also identified in the present study that the P53 signaling pathway was repressed. Previously, Mi et al (49) observed the upregulation of GADD45B and the downregulation of P53 in human prostate cancer cells exposed to silvestrol. This signaling pathway has been reported to correlate with the radioresponse of NSCLC (13). GADD45A is a target gene of P53 (50). Lambert et al (51) reported the upregulation of GADD45B mRNA in Saos-2-His273 cells exposed to proline rich membrane anchor 1, a P53-reactivating agent.

Benzopyrene is a carcinogen particularly associated with lung cancer (52); therefore, the normal lung cells were treated with benzopyrene in the present study to investigate the process of lung carcinogenesis. The harmful effects of benzopyrene against cell viability were observed by an MTT assay at various concentrations. Western blotting demonstrated that the expression of NF- $\mathrm{kB}$, Akt and GADD45B were increased over time in 
lung cells treated with benzopyrene, whereas the expression of cyclin B and P53 were decreased. This corresponded with the data that the AKT-MAPK pathway was activated via NF- $\mathrm{B}$, while the P53 pathway and cell cycle pathway were repressed; thus, GADD45B may contribute to lung carcinogenesis via activating the MAPK signaling pathway and repressing the P53 signaling and cell cycle pathways.

Although a series of comprehensive bioinformatics analyses and validation experiments were performed, there were two major limitations in the present study: i) Only one lung cell line was used in the current study, which may not eliminate the heterogeneity of lung cancer; ii) knockdown of GADD45B was not performed, and the expressions of other proteins after GADD45B knockdown were not considered, which may weaken the regulatory associations between them.

In addition to 'ECM-receptor interaction', 'P53 signaling pathway', 'cell adhesion molecules (CAMs)', 'focal adhesion' and 'cell cycle', it was also identified that the 'complement and coagulation cascades' pathway may be associated with the pathogenesis of lung cancer; therefore, it was speculated that GADD45B may contribute to lung carcinogenesis via activating the MAPK signaling pathway, and repressing the P53 signaling and cell cycle pathways. Thus, the role of this gene in lung cancer should be studied further; GADD45B siRNA knockdown experiments will assist the further validation of this speculation.

\section{Acknowledgements}

Not applicable.

\section{Funding}

No funding was received.

\section{Availability of data and material}

The datasets used and/or analyzed during the current study are available from the corresponding author on reasonable request.

\section{Authors' contributions}

$\mathrm{XJ}$ and JL were involved in the conception and design of the research and drafting the manuscript. $\mathrm{ZZ}$ participated in the acquisition of data. RX performed the analysis and interpretation of data. YG was involved in the statistical analysis, XL participated in the design of the study and performed the statistical analysis. All authors read and approved the final manuscript.

\section{Ethics approval and consent to participate}

Not applicable.

\section{Patient consent for publication}

Not applicable.

\section{Competing interests}

The authors declare that they have no competing interests.

\section{References}

1. McGuire S: World cancer report 2014. Geneva, switzerland: World health organization, international agency for research on cancer, WHO Press, 2015. Adv Nutr 7: 418-419, 2016.

2. Travis WD, Travis LB and Devesa SS: Lung cancer. Cancer 75 (Suppl 1): S191-S202, 1995.

3. Ahrendt SA, Decker PA, Alawi EA, Zhu Yr YR, Sanchez-Cespedes M, Yang SC, Haasler GB, Kajdacsy-Balla A, Demeure MJ and Sidransky D: Cigarette smoking is strongly associated with mutation of the K-ras gene in patients with primary adenocarcinoma of the lung. Cancer 92: 1525-1530, 2001.

4. Naoki K, Chen TH, Richards WG, Sugarbaker DJ and Meyerson M: Missense mutations of the BRAF gene in human lung adenocarcinoma. Cancer Res 62: 7001-7003, 2002.

5. Weir BA, Woo MS, Getz G, Perner S, Ding L, Beroukhim R, Lin WM, Province MA, Kraja A, Johnson LA, et al: Characterizing the cancer genome in lung adenocarcinoma. Nature 450: 893-898, 2007.

6. Engels EA, Wu X, Gu J, Dong Q, Liu J and Spitz MR: Systematic evaluation of genetic variants in the inflammation pathway and risk of lung cancer. Cancer Res 67: 6520-6527, 2007.

7. Wenzlaff AS, Cote ML, Bock CH, Land SJ, Santer SK, Schwartz DR and Schwartz AG: CYP1A1 and CYP1B1 polymorphisms and risk of lung cancer among never smokers: A population-based study. Carcinogenesis 26: 2207-2212, 2005.

8. Lin Z, Zhang X, Tuo J, Guo Y, Green B, Chan CC, Tan W, Huang Y, Ling W, Kadlubar FF, et al: A variant of the Cockayne syndrome B gene ERCC6 confers risk of lung cancer. Hum Mutat 29: 113-122, 2008.

9. Amos CI, Wu X, Broderick P, Gorlov IP, Gu J, Eisen T, Dong Q, Zhang Q, Gu X, Vijayakrishnan J, et al: Genome-wide association scan of tag SNPs identifies a susceptibility locus for lung cancer at 15q25.1. Nat Genet 40: 616-622, 2008.

10. Westhoff B, Colaluca IN, D'Ario G, Donzelli M, Tosoni D, Volorio S, Pelosi G, Spaggiari L, Mazzarol G, Viale G, et al: Alterations of the Notch pathway in lung cancer. Proc Natl Acad Sci USA 106: 22293-22298, 2009.

11. Leidner RS, Fu P, Clifford B, Hamdan A, Jin C, Eisenberg R, Boggon TJ, Skokan M, Franklin WA, Cappuzzo F, et al: Genetic abnormalities of the EGFR pathway in African American Patients with non-small-cell lung cancer. J Clin Oncol 27: 5620-5626, 2009.

12. Gustafson AM, Soldi R, Anderlind C, Scholand MB, Qian J, Zhang X, Cooper K, Walker D, McWilliams A, Liu G, et al: Airway PI3K pathway activation is an early and reversible event in lung cancer development. Sci Transl Med 2: 26ra25, 2010.

13. Jung IL, Kang HJ, Kim KC and Kim IG: PTEN/pAkt/p53 signaling pathway correlates with the radioresponse of non-small cell lung cancer. Int J Mol Med 25: 517-523, 2010.

14. Ding L, Getz G, Wheeler DA, Mardis ER, McLellan MD, Cibulskis K, Sougnez C, Greulich H, Muzny DM, Morgan MB, et al: Somatic mutations affect key pathways in lung adenocarcinoma. Nature 455: 1069-1075, 2008.

15. Bremnes RM, Veve R, Gabrielson E, Hirsch FR, Baron A, Bemis L, Gemmill RM, Drabkin HA and Franklin WA: High-throughput tissue microarray analysis used to evaluate biology and prognostic significance of the E-cadherin pathway in non-small-cell lung cancer. J Clin Oncol 20: 2417-2428, 2002.

16. Yanaihara N, Caplen N, Bowman E, Seike M, Kumamoto K, Yi M, Stephens RM, Okamoto A, Yokota J, Tanaka T, et al: Unique microRNA molecular profiles in lung cancer diagnosis and prognosis. Cancer Cell 9: 189-198, 2006.

17. Liu XG, Zhu WY, Huang YY, Ma LN, Zhou SQ, Wang YK, Zeng F, Zhou JH and Zhang YK: High expression of serum miR-21 and tumor miR-200c associated with poor prognosis in patients with lung cancer. Med Oncol 29: 618-626, 2012.

18. Landi MT, Dracheva T, Rotunno M, Figueroa JD, Liu H, Dasgupta A, Mann FE, Fukuoka J, Hames M, Bergen AW, et al: Gene expression signature of cigarette smoking and its role in lung adenocarcinoma development and survival. PLoS One 3: e1651, 2008.

19. Ogata H, Goto S, Sato K, Fujibuchi W, Bono H and Kanehisa M: KEGG: Kyoto encyclopedia of genes and genomes. Nucleic Acids Res 27: 29-34, 1999.

20. Joshi-Tope G, Gillespie M, Vastrik I, D'Eustachio P, Schmidt E, de Bono B, Jassal B, Gopinath GR, Wu GR, Matthews L, et al: Reactome: A knowledgebase of biological pathways. Nucleic Acids Res 33: D428-D432, 2005. 
21. Gautier L, Cope L, Bolstad BM and Irizarry RA: Affy-analysis of Affymetrix GeneChip data at the probe level. Bioinformatics 20: 307-315, 2004

22. Górecki $\mathrm{T}$ and Smaga $Ł$ : A comparison of tests for the one-way ANOVA problem for functional data. Computational Statistics 30: 987-1010, 2015.

23. Benjamini Y and Hochberg Y: Controlling the false discovery rate: A practical and powerful approach to multiple testing. J Royal Statistical Society. Series B (Methodological): 289-300, 1995.

24. Draghici S, Khatri P, Tarca AL, Amin K, Done A, Voichita C, Georgescu C and Romero R: A systems biology approach for pathway level analysis. Genome Res 17: 1537-1545, 2007.

25. Francesconi M, Remondini D, Neretti N, Sedivy JM, Cooper LN, Verondini E, Milanesi L and Castellani G: Reconstructing networks of pathways via significance analysis of their intersections. BMC Bioinformatics 9 (Suppl 4): S9, 2008.

26. Tarca AL, Draghici S, Khatri P, Hassan SS, Mittal P, Kim JS, Kim CJ, Kusanovic JP and Romero R: A novel signaling pathway impact analysis. Bioinformatics 25: 75-82, 2009.

27. Zhong G, Chen X, Fang X, Wang D, Xie M and Chen Q: Fra-1 is upregulated in lung cancer tissues and inhibits the apoptosis of lung cancer cells by the P53 signaling pathway. Oncol Rep 35 447-453, 2016

28. Havel LS, Kline ER, Salgueiro AM and Marcus AI: Vimentin regulates lung cancer cell adhesion through a VAV2-Rac1 pathway to control focal adhesion kinase activity. Oncogene 34 1979-1990, 2015

29. Corrales L, Ajona D, Rafail S, Lasarte JJ, Riezu-Boj JI Lambris JD, Rouzaut A, Pajares MJ, Montuenga LM and Pio R: Anaphylatoxin C5a creates a favorable microenvironment for lung cancer progression. J Immunol 189: 4674-4683, 2012.

30. Pappot H, Pedersen AN, Brünner N and Christensen IJ: The complex between urokinase (uPA) and its type-1 inhibitor (PAI-1) in pulmonary adenocarcinoma: Relation to prognosis. Lung Cancer 51: 193-200, 2006.

31. McVey JH: Tissue factor pathway. Baillieres Best Pract Res Clin Haematol 12: 361-372, 1999.

32. Currie MS, Vala M, Pisetsky DS, Greenberg CS, Crawford J and Cohen HJ: Correlation between erythrocyte CR1 reduction and other blood proteinase markers in patients with malignant and inflammatory disorders. Blood 75: 1699-1704, 1990.

33. Borensztajn K, Peppelenbosch MP and Spek CA: Coagulation Factor Xa inhibits cancer cell migration via LIMK1-mediated cofilin inactivation. Thromb Res 125: e323-e328, 2010.

34. Fan TW, Lane AN, Higashi RM, Farag MA, Gao H, Bousamra M and Miller DM: Altered regulation of metabolic pathways in human lung cancer discerned by (13)C stable isotope-resolved metabolomics (SIRM). Mol Cancer 8: 41, 2009.

35. Koukourakis MI, Giatromanolaki A and Sivridis E, Tumour and Angiogenesis Research Group: Lactate dehydrogenase isoenzymes 1 and 5: Differential expression by neoplastic and stromal cells in non-small cell lung cancer and other epithelial malignant tumors. Tumor Biol 24: 199-202, 2003.

36. Koukourakis MI, Giatromanolaki A, Sivridis E, Gatter KC and Harris AL, Tumor and Angiogenesis Research Group: Pyruvate dehydrogenase and pyruvate dehydrogenase kinase expression in non small cell lung cancer and tumor-associated stroma. Neoplasia 7: 1-6, 2005.

37. Yang P, Ebbert JO, Sun Z and Weinshilboum RM: Role of the glutathione metabolic pathway in lung cancer treatment and prognosis: A review. J Clin Oncol 24: 1761-1769, 2006.
38. Zanger UM, Turpeinen M, Klein K and Schwab M: Functional pharmacogenetics/genomics of human cytochromes P450 involved in drug biotransformation. Anal Bioanal Chem 392: 1093-1108, 2008

39. Tamura RE, de Vasconcellos JF, Sarkar D, Libermann TA, Fisher PB and Zerbini LF: GADD45 proteins: Central players in tumorigenesis. Curr Mol Med 12: 634-651, 2012.

40. Moskalev AA, Smit-McBride Z, Shaposhnikov MV, Plyusnina EN, Zhavoronkov A, Budovsky A, Tacutu R and Fraifeld VE: Gadd45 proteins: Relevance to aging, longevity and age-related pathologies. Ageing Res Rev 11: 51-66, 2012.

41. Azam N, Vairapandi M, Zhang W, Hoffman B and Liebermann DA: Interaction of CR6 (GADD45gamma) with proliferating cell nuclear antigen impedes negative growth control. J Biol Chem 276: 2766-2774, 2001.

42. Hosokawa S, Toyooka S, Fujiwara Y, Tokumo M, Soh J, Takigawa N, Hotta K, Yoshino T, Date H, Tanimoto M and Kiura K: Comprehensive analysis of EGFR signaling pathways in Japanese patients with non-small cell lung cancer. Lung Cancer 66: 107-113, 2009.

43. Gupta M, Gupta SK, Hoffman B and Liebermann DA: Gadd45a and Gadd45b protect hematopoietic cells from UV-induced apoptosis via distinct signaling pathways, including p38 activation and JNK inhibition. J Biol Chem 281: 17552-17558, 2006.

44. Takekawa M, Tatebayashi K, Itoh F, Adachi M, Imai K and Saito H: Smad-dependent GADD45beta expression mediates delayed activation of p38 MAP kinase by TGF-beta. EMBO J 21: 6473-6482, 2002.

45. Macias MJ, Martin-Malpartida $P$ and Massagué J: Structural determinants of Smad function in TGF- $\beta$ signaling. Trends Biochem Sci 40: 296-308, 2015.

46. Howley BV, Hussey GS, Link LA and Howe PH: Translational regulation of Inhibin $\beta$ A by TGF $\beta$ via the RNA-binding protein hnRNP E1 enhances the invasiveness of epithelial-to-mesenchymal transitioned cells. Oncogene 35: 1725-1735, 2016

47. Major MB and Jones DA: Identification of a gadd45beta 3'enhancer that mediates SMAD3- and SMAD4-dependent transcriptional induction by transforming growth factor beta. J Biol Chem 279: 5278-5287, 2004.

48. Vairapandi M, Balliet AG, Hoffman B and Liebermann DA GADD 45b and GADD45g are cdc2/cyclinB1 kinase inhibitors with a role in $\mathrm{S}$ and $\mathrm{G} 2 / \mathrm{M}$ cell cycle checkpoints induced by genotoxic stress. J Cell Physiol 192: 327-338, 2002.

49. Mi Q, Kim S, Hwang BY, Su BN, Chai H, Arbieva ZH, Kinghorn AD and Swanson SM: Silvestrol regulates G2/M checkpoint genes independent of p53 activity. Anticancer Res 26: 3349-3356, 2006.

50. Zhan Q: Gadd45a, a p53-and BRCA1-regulated stress protein, in cellular response to DNA damage. Mutat Res 569: 133-143, 2005.

51. Lambert JM, Moshfegh A, Hainaut P, Wiman KG and Bykov VJ: Mutant p53 reactivation by PRIMA-1MET induces multiple signaling pathways converging on apoptosis. Oncogene 29: $1329-1338,2010$

52. Denissenko MF, Pao A, Tang M and Pfeifer GP: Preferential formation of benzo[a]pyrene adducts at lung cancer mutational hotspots in p53. Science 274: 430-432, 1996.

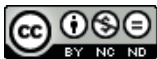

This work is licensed under a Creative Commons Attribution-NonCommercial-NoDerivatives 4.0 International (CC BY-NC-ND 4.0) License. 